\title{
A Rapid Electrophoresis Method on Agarose Gel to Characterise Dairy Protein Aggregates
}

\author{
Laetitia Gemelas$^{1}$, Pascal Degraeve ${ }^{2}$, Marion Morand ${ }^{3}$, Arnaud Hallier ${ }^{4}$, Yann Demarigny ${ }^{*}$ \\ ${ }^{1}$ Univ Lyon, ISARA Lyon, Université Lyon 1, BioDyMIA (Bioingénierie et Dynamique Microbienne aux Interfaces Alimentaires), \\ EA n³733, ISARA, Agrapôle, Lyon, France \\ ${ }^{2}$ Univ Lyon, Université Lyon 1, ISARA Lyon, BioDyMIA (Bioingénierie et Dynamique Microbienne aux Interfaces Alimentaires), \\ EA n³733, IUT Lyon 1, technopole Alimentec, rue Henri de Boissieu, BOURG-EN-BRESSE, France \\ ${ }^{3}$ General Mills Inc, One Global Dairy, Vienne Technical Center, Chemin des Mines Vienne, France \\ ${ }^{4}$ ISARA Lyon, Chemistry Laboratory, Lyon, France \\ Email: lgemelas@isara.fr, pascal.degraeve@univ-lyon1.fr, marion.morand@genmills.com, ahallier@isara.fr, \\ *ydemarigny@isara.fr
}

How to cite this paper: Gemelas, L., Degraeve, P., Morand, M., Hallier, A. and Demarigny, Y. (2018) A Rapid Electrophoresis Method on Agarose Gel to Characterise Dairy Protein Aggregates. Food and Nutrition Sciences, 9, 325-334. https://doi.org/10.4236/fns.2018.94025

Received: March 13, 2018

Accepted: April 23, 2018

Published: April 26, 2018

Copyright $\odot 2018$ by authors and Scientific Research Publishing Inc. This work is licensed under the Creative Commons Attribution International License (CC BY 4.0).

http://creativecommons.org/licenses/by/4.0/ (c) (i) Open Access

\begin{abstract}
Heat treatment of milk may cause whey proteins and caseins to form aggregates. These soluble and micellar aggregates and their other properties (size, composition, shape, etc.) can affect the techno-functionalities to the milk, conferring interesting or negative features depending on the application in dairy industries. In this study, we propose a new approach to characterise those protein aggregates. SDS-agarose electrophoresis is followed by the calculation of a retention factor $(\mathrm{R} f)$ for each protein spot. $\mathrm{R} f$ allows milk aggregates to be compared qualitatively under the same conditions. This method could be transposed to the dairy industry for a better knowledge of the milk subsequent to heat treatment.
\end{abstract}

\section{Keywords}

Heat Treatment of Milk, Dairy Protein Aggregates, Agarose Gel Electrophoresis

\section{Introduction}

In the dairy industry, heat treatments—-such as pasteurization-are widely used to stabilize the microbial evolution of the milk and increase the shelf-life of dairy products, or simply to cook the product. But meanwhile, the milk undergoes physico-chemical and biochemical changes; the proteins, especially, can be modified to a greater or lesser extent. At temperatures above $60^{\circ} \mathrm{C}$, soluble whey proteins ( $\beta$-Lactoglobulin, $\beta$-Lg, $\alpha$-Lactalbumin, $\alpha$-La, bovine serum albumin, 
BSA, immunoglobulin, Ig) start to unfold, allowing them to interact with caseins, mainly $\kappa$-casein $(\mathrm{CN}-\kappa)$ and $\alpha_{\mathrm{s} 2}$-casein $\left(\mathrm{CN}-\alpha_{\mathrm{s} 2}\right)$; this induces protein aggregation [1] [2]. Thiol-disulfide reactions mainly occur which lead to covalent bonds. However, ionic and hydrophobic interactions can also happen during the protein aggregation, especially during the initial phase of aggregation [1].

Several mechanisms describe aggregate formation [3]. Aggregate composition depends on the physico-chemical state of the milk and the intensity of the heat treatment (time and temperature). Regardless of mechanisms, different aggregates can be formed depending on the product (whey or milk) and their physico-chemical characteristics: a/denatured whey protein soluble aggregates, $\mathrm{b} /$ denatured whey proteins bonded to caseins under soluble or micellar forms. Soluble aggregates are defined here as protein structures found in the supernatant after centrifugation $(25,000 \mathrm{~g} / 30 \mathrm{~min})$. The pellets containing the micellar aggregates and the micellar caseins are recovered in the precipitate [4].

Protein aggregates formed in a milk heated between $85^{\circ} \mathrm{C}$ and $95^{\circ} \mathrm{C}$ for a few minutes lead to technological and rheological modifications thereafter [5]. During acid coagulation-in yoghurt and fermented milk processes-, the gelation $\mathrm{pH}$ of a pre-heated milk is higher than the raw milk: 5.3 vs. 4.6. The resultant acid gel is firmer and less porous (syneresis is therefore reduced during storage) than the gel of the raw milk [6]. During a cheese making process, it is well known that adding rennet to a pre-heated milk leads to a less cohesive gel-explained mainly by ion migrations inside casein micelles and also by the alteration of the enzymatic site of the chymosin. The alteration of clotting properties as a consequence of thermal treatment constitutes a technological defect inducing yield losses [7]. It is therefore essential to characterise aggregates formed during the different steps of the milk process following heat treatment. However, the methods currently used-such as SEC (Size-exclusion chromatography), FPLC (Fast Protein Liquid Chromatography) - require trained employees and expensive equipment [3] [8].

Agarose gel electrophoresis is frequently used, for instance to separate DNA fragments. But according to Wu et al. [9], it could also be employed to discriminate between and characterise proteins, even those with high molecular mass, i.e. superior to $330 \mathrm{kDa}$. In this study, we propose a new approach-cheaper and easier to implement in food companies-to characterize protein aggregates formed during the heat treatment of the milk.

\section{Materials and Methods}

Except when specified, all the chemical products were provided by Sigma-Aldrich (St-Quentin Fallavier, France).

\subsection{Sample Preparation}

Skim milk (Eurosérum, Saint-Martin-Belle-Roche, France) and whey powders (Eurosérum, Saint-Martin-Belle-Roche, France) were stored at $-20^{\circ} \mathrm{C}$ in her- 
metic bags and used within three months.

Milk and whey powders were reconstituted at $10 \%(\mathrm{w} / \mathrm{v})$ in distilled water and stirred during one hour at a rotation speed of $52 \mathrm{rad} / \mathrm{s}$. Sodium azide $(0.02 \%$ $\mathrm{w} / \mathrm{v}$ ) was then added to prevent the growth of gram negative bacteria. Samples were given 12 hours to equilibrate at ambient temperature without agitation.

\section{2. $\mathrm{pH}$ and Acidity}

$\mathrm{pH}$ and acidity were measured in triplicate before the heat treatment of the milk (see below). $\mathrm{pH}$ was measured using a PHM210 Standard pH Meter (Meter$\left.\mathrm{Lab}^{\circledR}\right)$. Titratable acidity was determined according to the Dornic method $\left({ }^{\circ} \mathrm{D}\right.$, with $1^{\circ} \mathrm{D}=0.01 \%$ lactic acid) [10].

\subsection{Heat Treatment}

Glass tubes (volume $8 \mathrm{~mL}$, diameter $5 \mathrm{~mm}$ ) were cleaned with hot nitric acid and rinsed with distilled water. The tubes were then filled with $4 \mathrm{~mL}$ of sample and closed with a screw cap. The samples were heated for $6 \mathrm{~min}$ in a water-bath at $92^{\circ} \mathrm{C}$ and then cooled at once in an ice-water bath.

\subsection{Preparation of Samples for Electrophoresis}

Two fractions of pre-heated milk-the supernatant and the pellet-were obtained by centrifugation as follows: $2 \mathrm{~mL}$ of pre-heated milk poured into a 2 mL-tube were centrifuged at 25,000 g during $60 \mathrm{~min}$ at $20^{\circ} \mathrm{C}$ in an Eppendorf centrifuge Type 5417R (microcentrifuge, Eppendorf, Montesson, France). These last parameters of centrifugation have been optimized in intern but the results are not shown. After centrifugation, the supernatant-containing soluble aggregates-was separated from the precipitate, i.e. the pellets-containing micellar aggregates. The two fractions were diluted equally ( 1 to 1$)$ in the sample buffer. This buffer contained $0.6 \mathrm{M}$ Tris- $\mathrm{HCl} \mathrm{pH} 6.8,10 \%$ (v/v) glycerol, $0.036 \%(\mathrm{w} / \mathrm{v})$ bromophenol blue (Biorad Laboratories, Hercules, US). The supernatant and the control milk were homogenised using an agitator (Edmund Bühler, Hechingen, Germany) rotating at $420 \mathrm{rpm}$ during $1 \mathrm{~h}$ at ambient temperature. The pellets were first solubilized in the sample buffer by mechanic action and then agitated at $420 \mathrm{rpm}$ for $12 \mathrm{~h}$. One gram of whey powder was diluted in $10 \mathrm{~mL}$ of sterile distilled water before the addition of the sample buffer. The samples-control milk, reference whey, supernatant of pre-heated milk, pellets of pre-heated milk, external standard (thyroglobulin) - were all frozen at $-20^{\circ} \mathrm{C}$ before use.

\subsection{SDS-Agarose Gel Electrophoresis}

SDS-agarose gels contained $0.4 \%(\mathrm{w} / \mathrm{v})$ agarose. The electrophoresis buffer contained $0.1 \mathrm{M}$ tris acetate, $0.003 \mathrm{M}$ EDTA, $0.1 \%(\mathrm{w} / \mathrm{v})$ SDS. The $\mathrm{pH}$ was set at 7.9 with pure acetic acid. Samples were put in the SDS-agarose gel and the gels were run in a horizontal electrophoresis system (Mini-Sub Cell GT $-7 \times 10 \mathrm{~cm}(\mathrm{~W} \mathrm{x}$ L) - and PowerPac ${ }^{\mathrm{Tm}}$ Basic Power Supply, Biorad, Corston, UK) at a constant 
voltage of $50 \mathrm{~V}$ for 2 to $3 \mathrm{~h}$. The gels were stained for $1 \mathrm{~h}$ in a dye solution containing 0.04\% (w/v) Coomassie brilliant blue R250 (Biorad Laboratories), 40\% $(\mathrm{v} / \mathrm{v})$ ethanol $96^{\circ}, 10 \%(\mathrm{v} / \mathrm{v})$ glacial acetic acid. The gels were first washed in distilled water during $15 \mathrm{~min}$ then for $30 \mathrm{~min}$ four times in succession in a solution composed of $30 \%(\mathrm{v} / \mathrm{v})$ ethanol and $10 \%(\mathrm{v} / \mathrm{v})$ glacial acetic acid. The gels were scanned and analysed using the ImageQuant ${ }^{\mathrm{TM}}$ TL 8.1 software (GE Healthcare Life Sciences, 2011).

\subsection{Preparation of the External Standard}

Five grams of thyroglobulin from bovine thyroid were solubilized in $100 \mathrm{~mL}$ of sterile distilled water. An equal volume of the thyroglobulin solution was diluted in the sample buffer. The thyroglobulin, used as an external standard electrophoresis, is formed of two subunits of about $330 \mathrm{kDa}$.

\subsection{Characterisation of the Aggregates}

For each spot observed on a track on the electrophoresis gel, a retention factor $(\mathrm{R} f)$ was calculated (such as in chromatography). In our case, the retention factor was defined as the ratio between the distance covered by the protein aggregates (the middle of the spot) and the total length of the track (Figure 1). The retention factor of each spot-i.e. globular whey proteins, caseins, protein aggregates and thyroglobulin (external standard)-was determined using the ImageQuant software. Each spot was also marked out by a front and a back end along the track (Figure 1). We also calculated the retention factors corresponding to these two points, referred to later in this document as $\mathrm{R} f$ min and $\mathrm{R} f$ max. For the integration of each spot using ImageQuant software, which appeared as a density curve, $2.5 \%$ of the area was removed from each side to avoid taking account of the noise resulting from the gel dye.

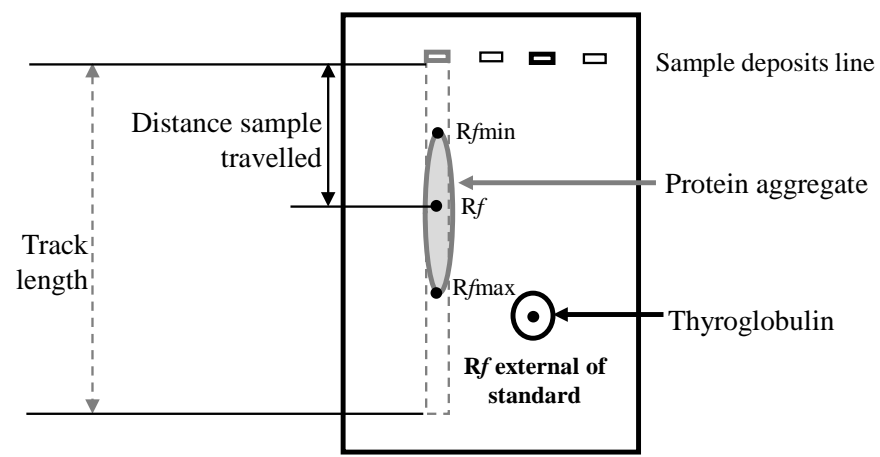

Figure 1. Graphical representation of an agarose gel. After migration, the retention factors of the protein aggregates (in grey) and the thyroglobulin (external standard, in black) were calculated: $\mathrm{R} f$ (ratio between the distance covered by the centre of the spot and the total length of the track), $\mathrm{R} f \mathrm{~min}$ (ratio between the distance covered by the front end of the spot and the total length of the track) and $R f \max$ (ratio between the distance covered by the back end of the spot and the total length of the track). 


\subsection{Statistics}

Each sample was analysed ten successive times in order to determine a 95\% confidence interval for each retention factor. The confidence interval was calculated as follows:

$$
m \pm t_{(n-1) \text { degree of freedom }} \cdot \sqrt{\left(s^{2} /(n-1)\right)}
$$

- with $m$ the mean, $s^{2}$ the variance and $n$ the number of sample-for a $5 \%$ threshold value for a $(n-1)$ degree of freedom. Two results were considered as significantly different $(\mathrm{p}<5 \%)$ if their mean \pm the standard-error did not overlap.

\section{Results and Discussion}

\section{1. $\mathrm{pH}$ and Acidity Measurement}

$\mathrm{pH}$ and acidity means were respectively equal to $6.66 \pm 0.05$ and $13.5 \pm 0.5^{\circ} \mathrm{D}$ for the control milk and $6.72 \pm 0.05$ and $16 \pm 0.5$ for the reference whey.

\subsection{Characterisation of Protein Aggregates}

The two extracts of pre-heated milk (supernatant and pellets) were analysed by agarose electrophoresis and compared with the corresponding control milk and reference whey, in order to characterise protein aggregates. The deciphering of the gels was based on the work of [4]. The protein bands on SDS-agarose showing on Figure 2 are sometimes diffuse. The methodology was improved later but this example is given anyway because all the different samples were analysed on the same SDS-agarose gel.

The whey proteins with low (between 14 and $18 \mathrm{kDa}$, spots $\mathrm{d}$ and $\mathrm{f}$ ) and high (between 66 and $83 \mathrm{kDa}$, spots b and e) molecular mass were both identified in the control milk sample and in the reference whey sample (Figure 2, tracks 1 and 2). Caseins were also spotted between 19 and $25 \mathrm{Da}$ (control milk: track 1spot c). As expected, aggregates only appeared in the pre-heated milk, in the supernatant as regards soluble aggregates (track 3-spot g) and in the pellets for the micellar aggregates (tracks 4-spot h). On the gel, a protein aggregate was observed both in the control milk sample and in the pellets of the pre-heated milk samples (track 1-spot a and track 4-spot i). We can notice that these spots were located on the gel above the high molecular mass whey proteins (track 1-spot a) and below the micellar aggregates (track 4-spot h). It could be argued, along with Guyomarc'h, et al. and Vasbinder et al. [2] [7] that these aggregates may be composed of $\mathrm{CN}-\kappa$ polymers.

\subsection{Characterisation of Protein Aggregates on SDS-Agarose Gel Using a New Approach}

Thyroglobulin (external standard) formed only one spot on the track with an $\mathrm{R} f$ value of $0.75 \pm 0.33$ (Figure 3 ).

Each spot on the gels constitutes a range of different types of protein aggregates or proteins and is characterised by the retention factors $\mathrm{R} f$, $\mathrm{R} f \mathrm{~min}$ and 
Rfmax (Figure 4). The retention factors of the external standard (thyroglobulin) were also characterised. To compare the results of protein migration across several agarose gels, we used this external standard as a reference. We calculated a ratio

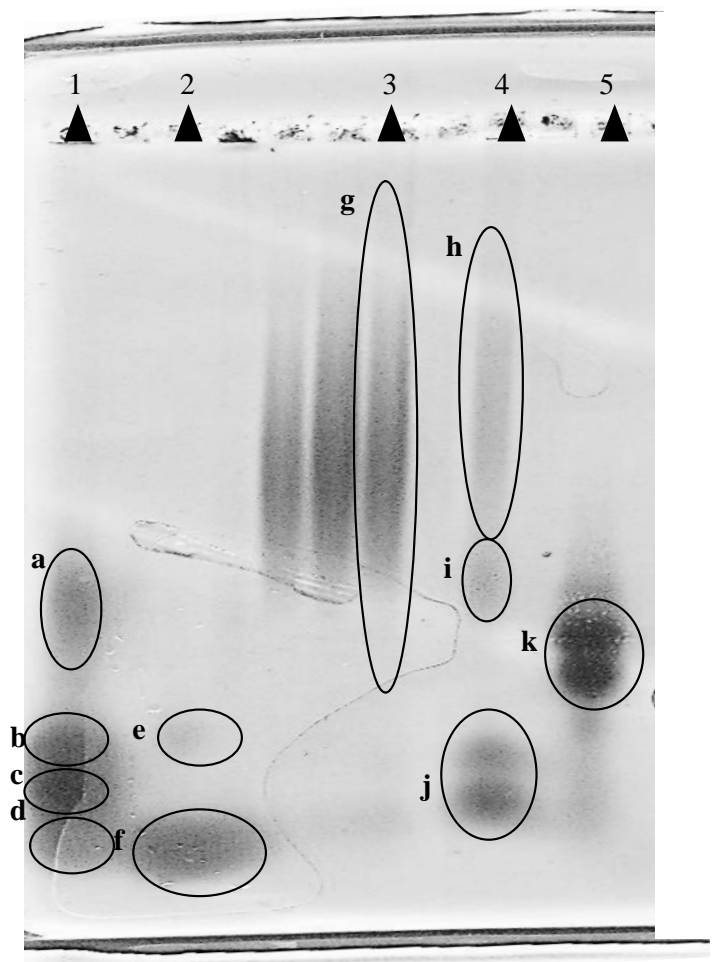

Figure 2. Protein profiles (monomers and aggregates) on SDS-agarose 1: control milk, 2: reference whey, 3: supernatant of pre-heated milk, 4: pellets of pre-heated milk, 5: external standard (thyroglobulin). The letters a to k correspond to protein spots: a and $\mathrm{i}$ : $\mathrm{CN}-\kappa$ polymers, $\mathrm{b}$ and e: high molecular mass of whey, $\mathrm{c}$ and $\mathrm{j}$ : caseins, $\mathrm{d}$ and $\mathrm{f}$ : low molecular mass of whey proteins, g: soluble aggregates and h: micellar aggregates.

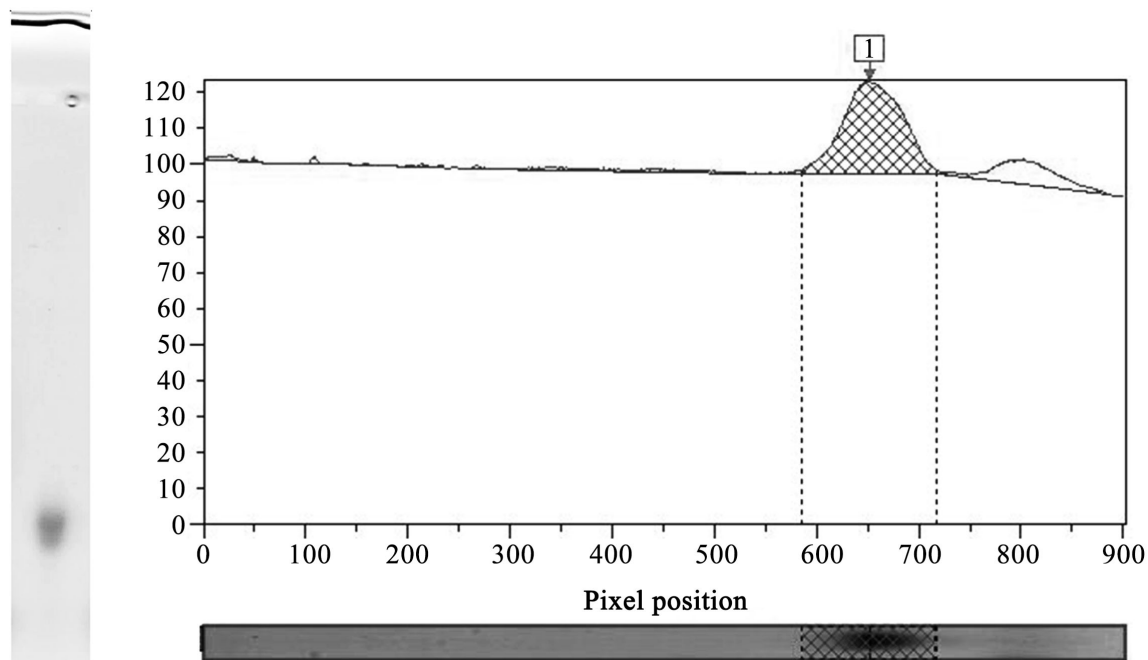

Figure 3. Protein profile of the external standard, the thyroglobulin. The $\mathrm{R} f$ of this protein appears on Figure 1. 


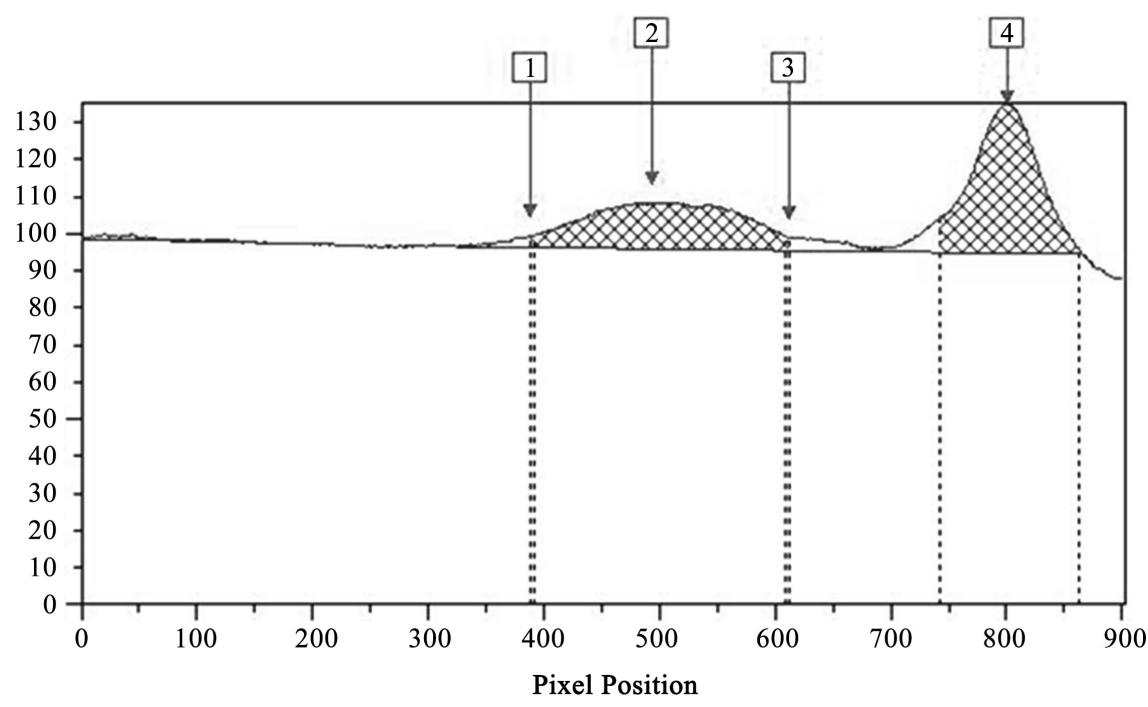

(a)

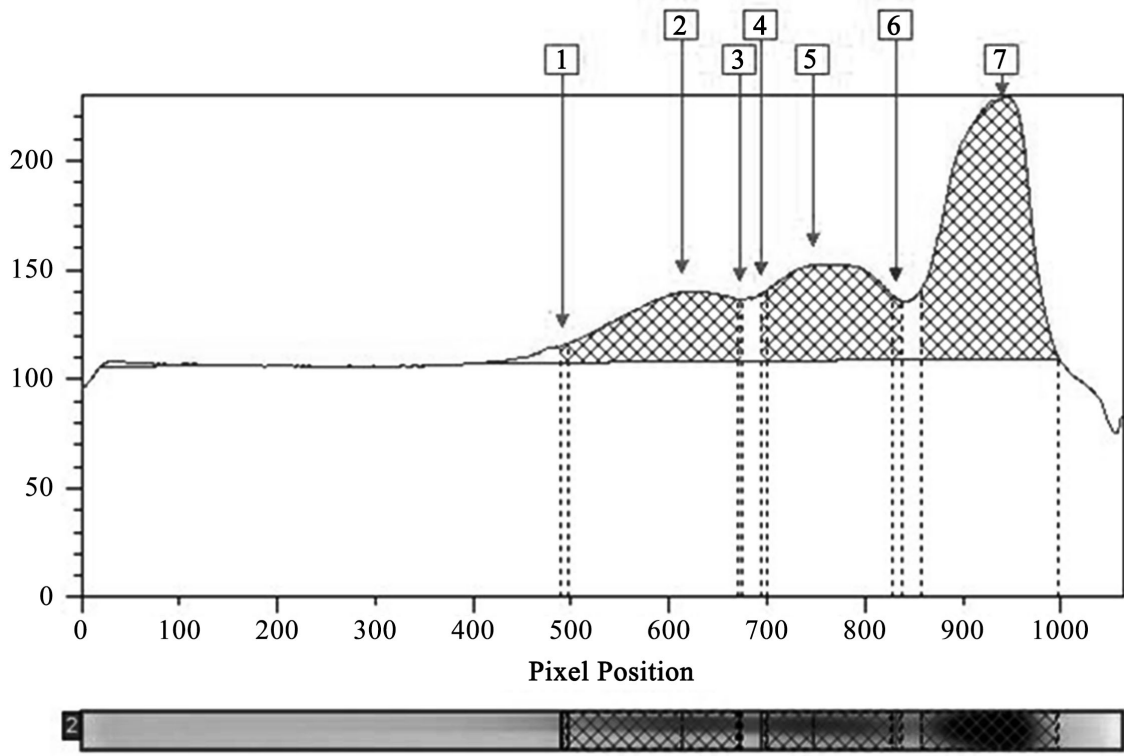

(b)

Figure 4. Example of protein profiles from the supernatant (a) and the pellets (b) of a pre-heated milk. (a) Soluble aggregates with $\mathrm{R} f \min (1), \mathrm{R} f(2), \mathrm{R} f \max (3)$, and whey proteins (4); (b) Micellar aggregates with $\mathrm{R} f \min (1), \mathrm{R} f(2), \mathrm{R} f \max (3), \mathrm{CN}-\kappa$ polymers with $\mathrm{R} f \min (4), \mathrm{R} f(5), \mathrm{R} f \max (6)$, and micellar caseins with $\mathrm{R} f(7)$.

" $\mathrm{R} t$ " for each protein spot between the $\mathrm{R} f$ of the spot and the $\mathrm{R} f$ of the thyroglobulin. Similarly, the $\mathrm{R} t \mathrm{~min}$ and $\mathrm{R}$ tmax of each spot were calculated. The $95 \%$ confident interval for $\mathrm{R} t, \mathrm{R} t \mathrm{~min}, \mathrm{R} t \mathrm{max}$ were $0.044,0.023$ and 0.048 respectively.

When two peaks overlap-as it is the case with the protein aggregates in the pellet shown in Figure 4(b) - only $\mathrm{R} t$ is taken into account to characterize the protein aggregates. Indeed, with a co-elution, the calculation of $\mathrm{R} t$ is more accurate than Rtmin and Rtmax. In order to improve the accuracy of the methodology, 
electrophoresis could be performed in a larger cell. In this last case, SDS-agarose gel would be the most appropriate, improving the separation of protein bands thanks to a broader track of migration. This would reduce or eliminate the overlapping of bands and would make possible the use of the parameters $\mathrm{R} t$ and $\mathrm{R}$ tmax. On the other hand, the low concentration of agarose in the gel low concentration of the agarose gel $(0.4 \% \mathrm{w} / \mathrm{w})$ would make it very weak and difficult to manipulate especially in the case of a long gel. It was for this last reason that electrophoresis was only performed on small SDS-agarose gel. Another solution consisted in increasing the agarose concentration to make gel manipulation easier, but this consequently decreased the size of pores, leading to poor protein separation with overlapping bands. This option was also excluded and the protocol retained was the one presented here.

\subsection{Comparison of Protein Aggregates Distribution}

The two spots corresponding respectively to the proteins in the control milk and the pellet of the pre-heated milk (Figure 2, track 1-spot a and track 4-spot i), both presumed to be $\mathrm{CN}-\kappa$ polymers, had the same $\mathrm{R} t$, and were consequently the same size ( $\mathrm{R} t \pm$ confident interval) (Figure 5 ). The $\mathrm{R} t$ of these two spots were significantly higher $(\mathrm{p}<5 \%)$ than the $R t$ of the soluble and micellar aggregates (Figure 2, track 3 spot $g$ and track 4 spot $\mathrm{h}$ ). We can postulate that the molecular size of the two former spots is lower that the size of the two latter spots. Besides, the colour of the spot was less intense before than after the heat-treatment. Although it is impossible to compare two different proteins on the basis of their colour intensity-the fixation of the colorant depends on their chemical composition and structure-, this criteria can be used to compare the same protein submitted to different conditions. Other authors have noticed that $\mathrm{CN}-\kappa$ polymers were more involved in the aggregation reactions with whey proteins than the monomeric form of $\mathrm{CN}-\kappa$ [2]. Following the procedure we developed, our observations led us to confirm the presence of polymerized forms of $\mathrm{CN}-\kappa$ in the samples of milk powder.

The Rtmin of micellar aggregates was significantly lower than that of soluble aggregates $(\mathrm{p}<5 \%)$ (Figure 5$)$. The spots corresponding to micellar aggregates were more spread out than the spots obtained with soluble aggregates. The upper fraction of the micellar aggregate spots included molecules characterised by a high molecular mass and/or a larger structure than the lower fraction of these same spots. To our knowledge, the comparison of the molecular characteristics, under the same conditions, of micellar and soluble aggregates has never previously been carried out. Guyomarc'h et al. (2003) highlighted the great reactivity of $\mathrm{CN}-\kappa$ polymers in the formation of protein aggregates induced by heat treatment of milk. On this basis, the $\mathrm{CN}-\kappa$ polymers-found in the micellar caseinsinvolved in micellar aggregation, would lead to an increase in the size of micellar aggregates but not that of soluble aggregates.

Concerning the small aggregate fractions, whatever their micellar or soluble 


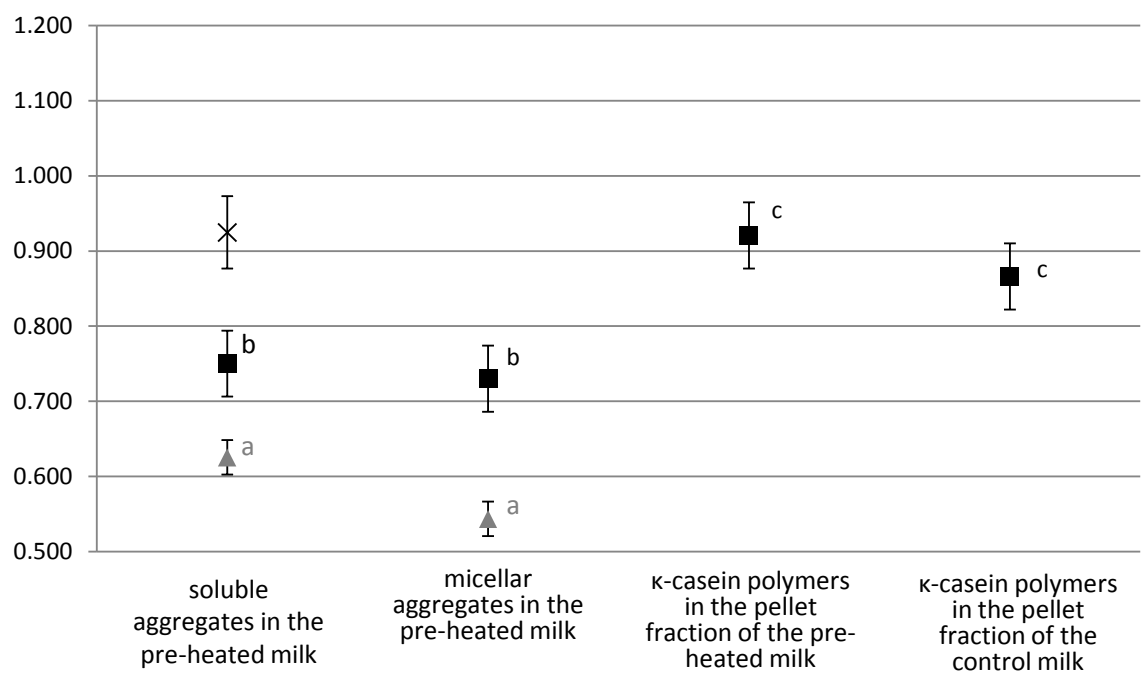

Figure 5. Distribution of the size of aggregates in samples ( $\mathrm{R} t$ values on $\mathrm{Y}$-axis). This is materialized by the retention factors: $\mathrm{R} t \min (\Delta), \mathrm{R} t(\boldsymbol{\square})$ and $\mathrm{R} t \max (\boldsymbol{*})$. The letter "a", "b" and "c" show significant differences between the distributions following the respective $95 \%$ confident intervals.

origin, we were not able to draw any conclusion. For instance, it was impossible to estimate the Rtmax of micellar aggregates since the spot partially overlapped with the one of $\mathrm{CN}-\kappa$ polymers. Further research will have to be carried out to improve the visual resolution in this technique.

\section{Conclusion}

In this article, we have proposed a technique to qualitatively evaluate the soluble and micellar aggregates formed during the heat treatment of milk. This methodology is based upon protein electrophoresis in agarose gel. Specific units, $\mathrm{R} t$, $\mathrm{R} t \mathrm{~min}, \mathrm{R} t \mathrm{max}$, defined in relation to an external standard-the thyroglobulinare calculated for each protein aggregate. Under the same analytical conditions, micellar aggregates appeared bigger than soluble aggregates. This methodology could be helpful in dairy research in order to study the presence of protein aggregates in dairy ingredients or subsequent to a heat treatment even though we are aware of the necessity to go on improving the methodology, especially for the detection of smaller-sized aggregates.

\section{Acknowledgements}

The authors would like to thank Carl HOLLAND for English revision.

\section{References}

[1] Anema, S.G. and Li, Y. (2003) Effect of pH on the Association of Denatured Whey Proteins with Casein Micelles in Heated Reconstituted Skim Milk. Journal of Agricultural and Food Chemistry, 51, 1640-1646. https://doi.org/10.1021/jf025673a

[2] Guyomarc'h, F., Law, A.J.R. and Dalgleish, D.G. (2003) Formation of Soluble and Micelle-Bound Protein Aggregates in Heated Milk. Journal of Agricultural and Food Chemistry, 51, 4652-4660. https://doi.org/10.1021/jf0211783 
[3] Donato, L. and Guyomarc'h, F. (2009) Formation and Properties of the Whey Protein/Kappa-Casein Complexes in Heated Skim Milk-A Review. Dairy Science \& Technology, 89, 3-29. https://doi.org/10.1051/dst:2008033

[4] Vasbinder, A.J., Alting A.C. and de Kruif, K.G. (2003) Quantification of Heat-Induced Casein-Whey Protein Interactions in Milk and Its Relation to Gelation Kinetics. Colloids and Surfaces B: Biointerfaces, 31, 115-123. https://doi.org/10.1016/S0927-7765(03)00048-1

[5] Anema, S.G., Lee, S.K., Lowe, E.K. and Klostermeyer, H. (2004) Rheological Properties of Acid Gels Prepared from Heated pH-Adjusted Skim Milk. Journal of Agricultural and Food Chemistry, 52, 337-343. https://doi.org/10.1021/jf034972c

[6] Jean, K., Renan, M., Famelart, M.H. and Guyomarc'h, F. (2006) Structure and Surface Properties of the Serum Heat-Induced Protein Aggregates Isolated from Heated Skim Milk. International Dairy Journal, 16, 303-315.

https://doi.org/10.1016/j.idairyj.2005.04.001

[7] Vasbinder, A.J., Rollema, H.S. and de Kruif, C.G. (2003) Impaired Rennetability of Heated Milk; Study of Enzymatic Hydrolysis and Gelation Kinetics. Journal of Dairy Science, 86, 1548-1555. https://doi.org/10.3168/jds.S0022-0302(03)73740-0

[8] Schokker, E.P., Singh, H. and Creamer, L.K. (2000) Heat-Induced Aggregation of $\beta$-Lactoglobulin $\mathrm{A}$ and $\mathrm{B}$ with $\alpha$-Lactalbumin. International Dairy Journal, 10 , 843-853. https://doi.org/10.1016/S0958-6946(01)00022-X

[9] Wu, M. and Kusukawa, N. (1998) SDS Agarose Gels for Analysis of Proteins. Biotechniques, 24, 676-679.

[10] Robinson, R.K. and Wilbey, R.A. (1998) Tests for Acidity and Chemical Analysis in Process Control. Cheesemaking Practice. Springer US, Boston. 